\title{
Physiological Functions of the COPI Complex in Higher Plants
}

\author{
Hee-Kyung Ahn ${ }^{1,5}$, Yong Won Kang ${ }^{1,2,5}$, Hye Min Lim ${ }^{1,3,5}$, Inhwan Hwang ${ }^{4}$, and Hyun-Sook Pai' *
}

\begin{abstract}
COPI vesicles are essential to the retrograde transport of proteins in the early secretory pathway. The COPI coatomer complex consists of seven subunits, termed $\alpha-, \beta-$ $\beta^{\prime}-, \gamma-, \delta-, \varepsilon-$, and $\zeta-C O P$, in yeast and mammals. Plant genomes have homologs of these subunits, but the essentiality of their cellular functions has hampered the functional characterization of the subunit genes in plants. Here we have employed virus-induced gene silencing (VIGS) and dexamethasone (DEX)-inducible RNAi of the COPI subunit genes to study the in vivo functions of the COPI coatomer complex in plants. The $\beta^{\prime}-, \gamma-$, and $\delta$-COP subunits localized to the Golgi as GFP-fusion proteins and interacted with each other in the Golgi. Silencing of $\beta^{\prime}, \gamma$, and $\delta$-COP by VIGS resulted in growth arrest and acute plant death in Nicotiana benthamiana, with the affected leaf cells exhibiting morphological markers of programmed cell death. Depletion of the COPI subunits resulted in disruption of the Golgi structure and accumulation of autolysosome-like structures in earlier stages of gene silencing. In tobacco $B Y-2$ cells, DEX-inducible RNAi of $\beta^{\prime}$-COP caused aberrant cell plate formation during cytokinesis. Collectively, these results suggest that COPI vesicles are essential to plant growth and survival by maintaining the Golgi apparatus and modulating cell plate formation.
\end{abstract}

\section{INTRODUCTION}

The endomembrane system of plants is very similar to those found in other eukaryotes, and is comprised of the endoplasmic reticulum (ER), the Golgi apparatus, endosomes, vacuoles, and the plasma membrane (Jürgens, 2004). The Golgi apparatus is composed of multiple stacks of cisternae, which can be further

\footnotetext{
${ }^{1}$ Department of Systems Biology, Yonsei University, Seoul 120-749, Korea, ${ }^{2}$ Biospectrum Life Science Institute, Seongnam 462-120, Korea, ${ }^{3}$ Department of Pharmacology and Brain Korea 21 PLUS Project for Medical Science, Yonsei University College of Medicine, Seoul 120-752, Korea, ${ }^{4}$ Division of Molecular and Life Sciences, Pohang University of Science and Technology, Pohang 790-784, Korea, ${ }^{5}$ These authors contributed equally to this work.

*Correspondence: hspai@yonsei.ac.kr
}

Received 4 May, 2015; revised 29 June, 2015; accepted 6 July, 2015; published online 2 October, 2015

Keywords: autophagy, cell death, cell plate formation, COPI vesicle, Golgi localization, virus-induced gene silencing divided into three parts; the cis-, medial-, and trans-Golgi (Papanikou and Glick, 2014). Each cisterna within the Golgi apparatus has a distinct set of proteins and enzymes that enable the processing of numerous proteins, including those trafficked to the vacuoles or secreted to the cell wall (Day et al., 2013; Frigerio et al., 2008; McFarlane et al., 2014).

Coated vesicles (COPI, COPII, and clathrin) are responsible for trafficking proteins throughout the endomembrane system (Paul and Frigerio, 2007). COPII vesicles mediate the anterograde transport from ER to Golgi, while clathrin-coated vesicles transfer proteins out of the trans-Golgi network, or transfer materials endocytosed from the cell surface (Jürgens, 2004). COPI vesicles are responsible for the retrograde transport of proteins from the Golgi to the ER, and for intra-Golgi transport (Paul and Frigerio, 2007). COPI is a heptameric complex composed of $\alpha$, $\beta, \beta^{\prime}, \gamma, \delta, \varepsilon$, and $\zeta$ subunits (Jackson, 2014). The components are recruited en bloc onto nascent Golgi vesicles by ARF1 GTPase to form the coat of the COPI vesicles (Hara-Kuge et al., 1994; Montesinos et al., 2014). COPI is especially important in the retention of organelle-specific proteins in its place, maintaining the unique property of each organelle (Gao et al., 2014). Recent studies have revealed that there are subpopulations of $\mathrm{COPI}$ vesicles; one group transports vesicles to the ER, while the other group moves within the Golgi (Donohoe et al., 2007; Gao et al., 2012). Although such subpopulations were initially distinguished by EM (Donohoe et al. 2007), recent studies in Arabidopsis have implied that subpopulations of COPI vesicles may be comprised of different isoforms of COPI subunits (Gao et al., 2012).

Unlike the formation of the cleavage furrow in animal cells for cytokinesis, plant cells generate phragmoplasts that enable the deposition of membrane vesicles in the middle of the division zone to form the cell plate (Jürgens, 2005a). The phragmoplast is a complex assembly of microtubules, microfilaments, and endoplasmic reticulum elements, and it controls the trafficking of secretory vesicles, originating from the trans-Golgi network/early endosome, to the division plane for the delivery of newly synthesized proteins and cell-wall polysaccharides (Assaad, 2001; Staehelin and Hepler, 1996). Golgi stacks consistently accumulate near the phragmoplast during telophase and cytokinesis (McMichael and Bednarek, 2013; Nebenführ et al., 2000). Recent studies have revealed the machinery used in cell-plate vesicle trafficking, which includes Rab/Ypt family GTPases, TRAPPI/TRAPPII, the exocyst complex, the cytokinesis-specific t-SNARE (KNOLLE), a syntaxin-binding protein (KEULE), and dynamin-related proteins (Jürgens, 2005b; McMichael and Bednarek, 2013; Van 
Damme et al., 2008). These proteins play a role in the directional transport, docking, and fusion of cell-plate-destined vesicles. However, the molecular machinery involved in the formation of cell-plate-building vesicles has not been properly characterized.

In plants, the presence of $\gamma$-COP proteins was detected in the vesicles proximal to the Golgi apparatus based on immunolabeling and in vitro reconstitution experiments (Pimpl et al., 2000). Ritzenthaler et al. (2002) used brefeldin A (BFA), which blocks the formation of COPI vesicles and clathrin vesicles, to elucidate the function of these vesicles. Further studies revealed the protein characteristics and in planta functions of regulators of COPI vesicle formation, notably the ARF1 GTPase and its regulator, the nucleotide exchange factor GNOM (Geldner et al., 2003), and the ARF1 GTPase-activating proteins (ArfGAPs) that stimulate the uncoating reaction for vesicle fusion with the target membrane (Min et al., 2013). However, the effect of COPI vesicle components silenced per se has not been assessed in plants.

In this study, we investigated the subcellular localization, protein interaction, and physiological functions of $\beta^{\prime}-, \gamma-$, and $\delta$ COP subunits in Nicotiana benthamiana and tobacco BY-2 cells. Our results suggest that the COPI complex is involved in Golgi maintenance and cell-plate formation, and that its prolonged depletion induces programmed cell death in plants.

\section{MATERIALS AND METHODS}

\section{Bimolecular fluorescence complementation (BiFC)}

BiFC analyses were performed as described (Ahn et al., 2011). The coding regions of $N$. benthamiana $\beta^{\prime}$ - and $\delta$-COP were amplified by polymerase chain reaction (PCR) and cloned into the pSPYNE vector containing the $\mathrm{N}$-terminal region of yellow fluorescent protein (YFP ${ }^{\mathrm{N}}$; amino acid residues 1-155). Similarly, the $\gamma$ and $\delta$-COP cDNAs were cloned into pSPYCE vector containing the C-terminal region of YFP (YFP'; residues 156239). The pSPYNE and pSPYCE fusion constructs were agroinfiltrated together into the leaves of 3-week-old $N$. benthamiana plants as described (Walter et al., 2004). After $48 \mathrm{~h}$, protoplasts were generated and the YFP signal was detected using a confocal laser scanning microsope (Zeiss LSM510) and fluorescence microscope.

\section{Virus-induced gene silencing (VIGS)}

VIGS was performed in $N$. benthamiana as described (Lee et al., 2013). N. benthamiana $\beta^{\prime}-, \gamma$, and $\delta$-COP genes were PCRamplified using the following specific primers: $\beta^{\prime}$-COP $\left(5^{\prime}-\right.$ ggatccatgcctccgaggctgga- $3^{\prime}$ and $5^{\prime}$-gggcccctttatagtc cgatcaag- $3^{\prime}$ ), $\gamma$-COP (5'-ggatccaagaccgggaatga- $3^{\prime}$ and $5^{\prime}$-gggcccacaacgttcaac- $\left.3^{\prime}\right)$, and $\delta$-COP $\left(5^{\prime}\right.$-ggatccggtggtgtcagca- $3^{\prime}$ and $5^{\prime}$-gggccettctagtgctccact$\left.3^{\prime}\right)$.

VIGS in Arabidopsis was carried out as described (BurchSmith et al., 2006). Arabidopsis $\delta$-COP (At5g05010) was PCRamplified using specific primers (5'-gaattcatggttgtgcttgctgct- $3^{\prime}$ and $5^{\prime}$-ggtaccaatactgcttcacctggg- $3^{\prime}$ ). The amplified cDNA fragment was cloned into the TRV2 vector using BamHI/Kpnl sites to generate TRV2: $\delta$-COP, which was subsequently transformed into Agrobacterium tumefaciens (strain C58C1). The recombinant Agrobacterium strains were grown overnight in LB media containing $10 \mathrm{mM}$ MES-KOH (pH 5.7) and $20 \mu \mathrm{M}$ acetosyringone, induced in induction media [10 $\mathrm{mM} \mathrm{MgCl}_{2}, 10 \mathrm{mM}$ MES$\mathrm{KOH}\left(\mathrm{pH} 5.7\right.$ ), and $200 \mu \mathrm{M}$ acetosyringone] at $\mathrm{OD}_{600}$ of $\sim 1.5$ for 3-5 $\mathrm{h}$, and then infiltrated into leaves of the ST-GFP-expressing transgenic Arabidopsis plants at 15 days after germination.

\section{Flow cytometry}

Nuclei were extracted from leaves of the VIGS plants and analyzed by flow cytometry as described (Kim et al., 2006).

Terminal deoxynucleotidyl transferase dUTP nick end labeling (TUNEL) assay

The TUNEL assay was performed with leaves of the VIGS plants as described (Ahn et al., 2011).

Staining with lysotracker red (LTR) and monodansylcadaverine (MDC)

LTR and MDC staining were performed as described (Kang et al., 2012).

\section{Transmission electron microscopy}

TRV and TRV: $\beta$ '-COP leaves at 12 days after infiltration (DAI) underwent transmission electron microscopy as described (Kang et al., 2010).

\section{Generation of DEX-inducible $\beta$ 'COP RNAi BY-2 cell lines}

BY-2 cells were transformed with the DEX-inducible $\beta^{\prime}-C O P$ RNAi construct based on the sense and anti-sense sequence of a 502-bp cDNA fragment of $N$. benthamiana $\beta$-COP as described (Ahn et al., 2011). For the induction of RNAi, the transgenic BY-2 cells were grown on medium containing $15 \mu \mathrm{M}$ DEX in ethanol $(0.033 \%)$.

\section{Staining of $B Y-2$ cells}

BY-2 cells were co-stained with aniline blue and 4',6-diamidino2-phenylindole (DAPI) to observe the nuclei and cell plate as described (Van Damme et al., 2006). Double-labeling of BY-2 cells with calcofluor staining and anti- $\alpha$-tubulin antibodies was performed to observe the cell plate and phragmoplasts as described (Nishihama et al., 2002).

\section{RESULTS}

Golgi localization and protein interactions of COPI subunits

The COPI coatomer complex is composed of 7 subunits $\alpha-, \beta-$, $\beta^{\prime}-, \gamma-, \delta-, \varepsilon-$, and $\zeta-\mathrm{COP}$, and corresponding homologs are present in the Arabidopsis and Nicotiana benthamiana genomes. We selected $\beta^{\prime}, \gamma$, and $\delta$-COP to determine physiological functions of the COPI subunits in plants. Supplementary Figures $\mathrm{S} 1$ and S2 present the nucleotide and amino acid sequences of $N$. benthamiana $\beta^{\prime}-, \gamma$, and $\delta$-COP genes, respectively. COPI vesicles were found in the proximity of the Golgi apparatus according to immunogold labeling studies (Pimpl et al., 2000). In order to determine more clearly the subcellular localization of COPI subunits, GFP fusion proteins of $\beta^{\prime}-, \gamma-$, and $\delta$-COP were expressed in $N$. benthamiana leaves via agroinfiltration, together with the Golgi marker G-RK (Nelson et al., 2007; Fig. 1A). Confocal laser scanning microscopy of the protoplasts prepared from the infiltrated leaves revealed overlapping patterns of green fluorescence from GFP-fused $\beta^{\prime}-, \gamma$-, and $\delta$-COP, and red fluorescence of G-RK as numerous spots in the cytosol (Fig 1A). Thus, the COPI subunits appear to localize to the Golgi apparatus in plants

COPI is a heptameric protein complex, which functions only when all its subunits are bound together (Jackson, 2014). We used bimolecular fluorescence complementation (BiFC) to examine the interactions between COPI subunits (Fig. 1B). YFP ${ }^{\mathrm{N}}$ and $\mathrm{YFP}^{\mathrm{C}}$-fused $\beta^{\prime}-, \gamma$-, and $\delta$-COP proteins were expressed in combination into $N$. benthamiana leaves by agroinfiltration. All 
Physiological Functions of the COPI Complex in Plants Hee-Kyung Ahn et al.
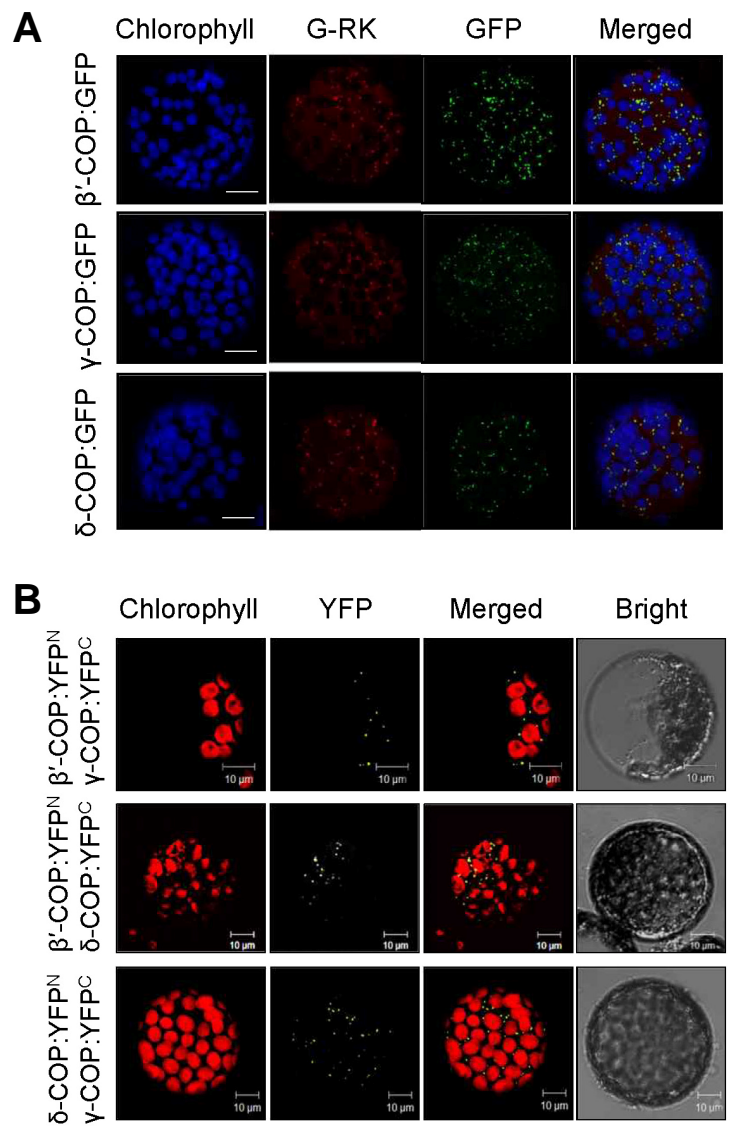

Fig. 1. Subcellular localization and protein interactions of COPI subunits. Each experiment was performed at least three times, and representative images are shown. (A) GFP-fusion proteins of $N$. benthamiana $\beta^{\prime}-, \gamma$-, and $\delta$-COP were expressed in $N$. benthamiana leaves through agroinfiltration, and GFP signal in leaf protoplasts was examined by confocal microscopy. To mark the Golgi complex, G-RK (red fluorescence) was co-expressed with the GFP fusion proteins. Chlorophyll autofluorescence is pseudo-colored blue. Scale bars $=10 \mu \mathrm{m}$. (B) BiFC was performed to detect in vivo interactions between $N$. benthamiana COPI subunits. $\beta^{\prime}-C O P: Y^{\prime} P^{N}$ and $\gamma$-COP:YFP ${ }^{C}, \beta^{\prime}-\mathrm{COP}: \mathrm{YFP}^{\mathrm{N}}$ and $\delta$-COP:YFP ${ }^{\mathrm{C}}$, and $\delta$-COP:YFP ${ }^{\mathrm{N}}$ and $\gamma$-COP:YFP ${ }^{C}$ were expressed together via agroinfiltration, and the YFP signal in leaf protoplasts was observed by confocal microscopy.

three combinations of COPI subunits $\left(\beta^{\prime}-\mathrm{COP}: \mathrm{YFP}^{\mathrm{N}}\right.$ and $\gamma$ COP:YFP ${ }^{C}, \beta^{\prime}-C O P: Y F P^{N}$ and $\delta$-COP:YFP ${ }^{C}$, and $\gamma$ - COP:YFP and $\delta$-COP:YFPC ${ }^{C}$ resulted in YFP fluorescence in the leaf protoplasts, displaying a pattern that resembles the Golgi pattern observed in Fig. 1A. However, no fluorescence was detected in the leaf protoplasts co-expressing $\beta^{\prime}-\mathrm{COP}: \mathrm{YFP}^{\mathrm{N}}$ and $\mathrm{YFP}^{\mathrm{C}}, \delta$ COP:YFP ${ }^{\mathrm{C}}$ and $\mathrm{YFP}^{\mathrm{C}}$, $\mathrm{YFP}^{\mathrm{N}}$ and $\gamma-\mathrm{COP}: \mathrm{YFP}^{\mathrm{C}}$, or $\mathrm{YFP}^{\mathrm{N}}$ and $\delta$ COP:YFP ${ }^{N}$ and YFP $^{C}$ as controls (Supplementary Fig. S3). These results suggest that the COPI subunits $\beta^{\prime}-, \gamma-$, and $\delta$ $\mathrm{COP}$ interact with each other at the Golgi apparatus.

VIGS of the COPI subunit genes results in acute plant cell death

Due to the essentiality of the gene function, it has been difficult

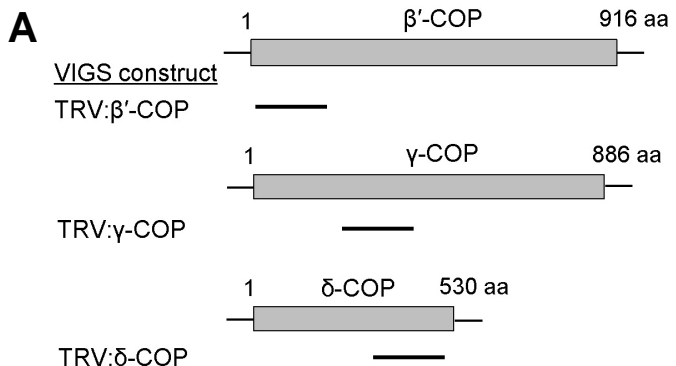

$\boldsymbol{B}$

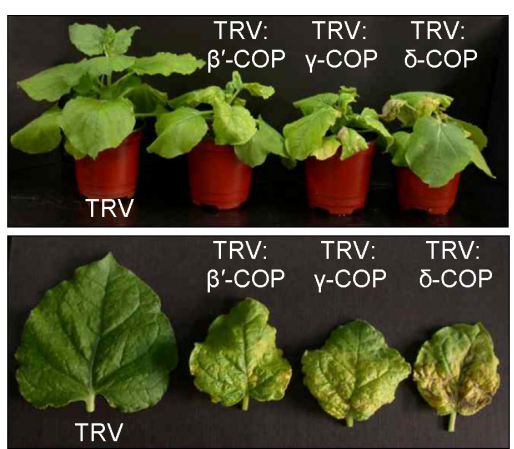

C

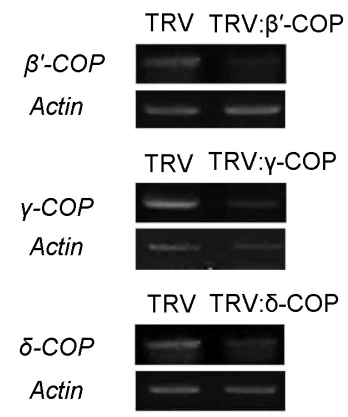

Fig. 2. Virus-induced gene silencing (VIGS) of COPI subunit genes in $N$. benthamiana. (A) Schematic drawing of $N$. benthamiana $\beta^{\prime}=, \gamma-$ , and $\delta$-COP genes and VIGS constructs. Bars indicate CDNA fragments of each gene cloned into the TRV vector. (B) VIGS phenotypes of $\beta^{\prime}, \gamma-$, and $\delta$-COP in comparison with the TRV control phenotype. The whole plants (top) and individual leaves (bottom) are shown at 20 days after infiltration (DAI). (C) Semiquantitative RTPCR to detect endogenous transcript levels. The actin mRNA leve was used as control. Total RNA was prepared from leaves collected from $>6$ independent VIGS plants. RT-PCR was performed three times, and a representative gel image is shown.

to characterize the loss-of-function phenotypes of the COPI subunit genes in plants (Bassham et al., 2008). Virus-induced gene silencing (VIGS) can be useful for analyzing embryo lethal genes during postembryonic developmental stages (BurchSmith et al., 2006; Ratcliff et al., 2001; Ruiz et al., 1998). To investigate the physiological functions of the COPI complex during plant development, we examined knockdown phenotypes after VIGS of $\beta^{\prime}-, \gamma$-, and $\delta$-COP in $N$. benthamiana (Fig. 2). VIGS was performed with partial cDNA fragments of the $N$. benthamiana $\beta^{\prime}-, \gamma$-, and $\delta$-COP genes cloned into a tobacco rattle virus (TRV)-based VIGS vector. TRV: $\beta^{\prime}-\mathrm{COP}, \mathrm{TRV}: \gamma-\mathrm{COP}$, 
A
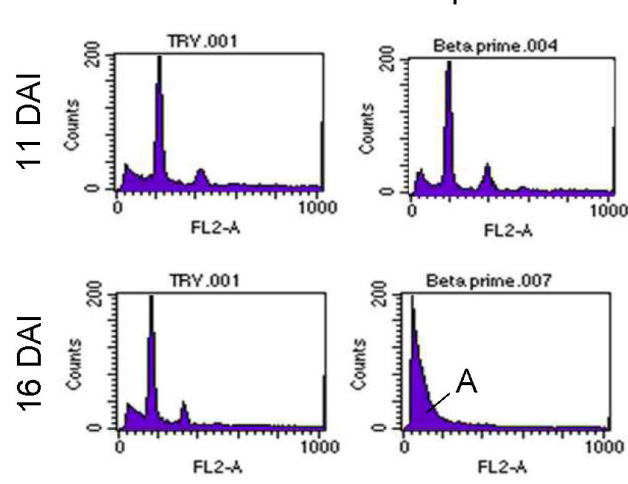

$\boldsymbol{B}$
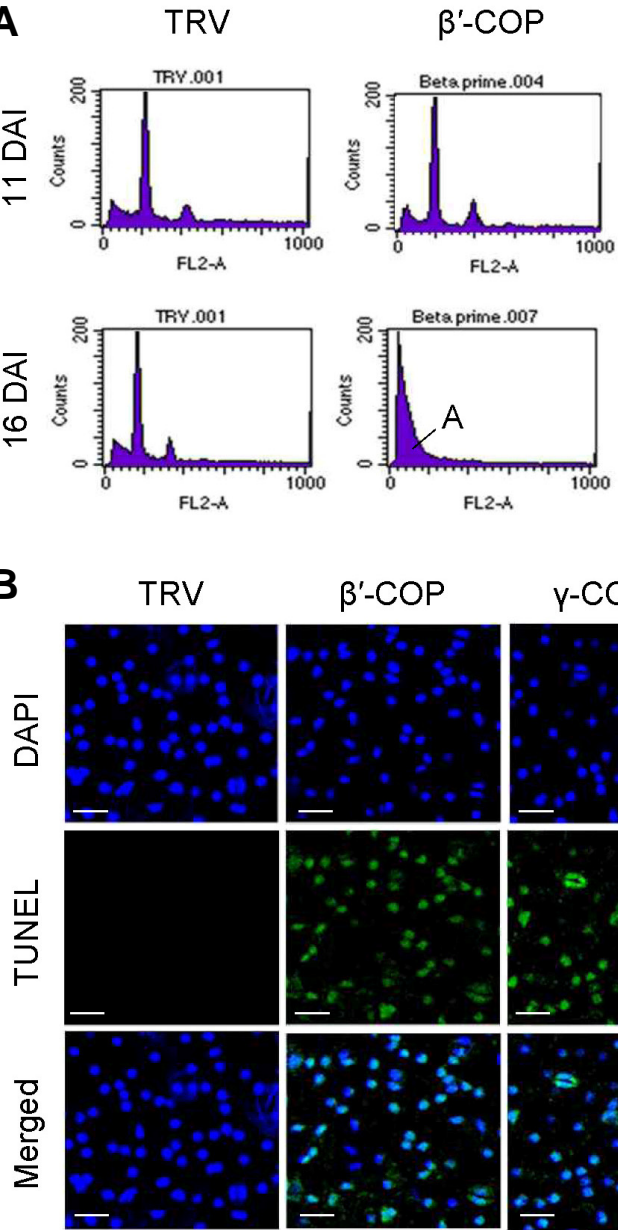

$\beta^{\prime}-\mathrm{COP}$

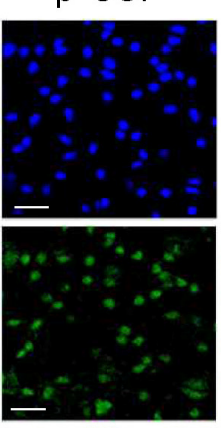

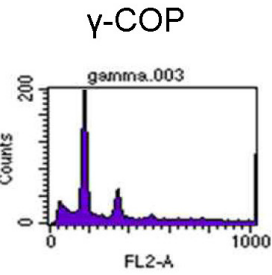
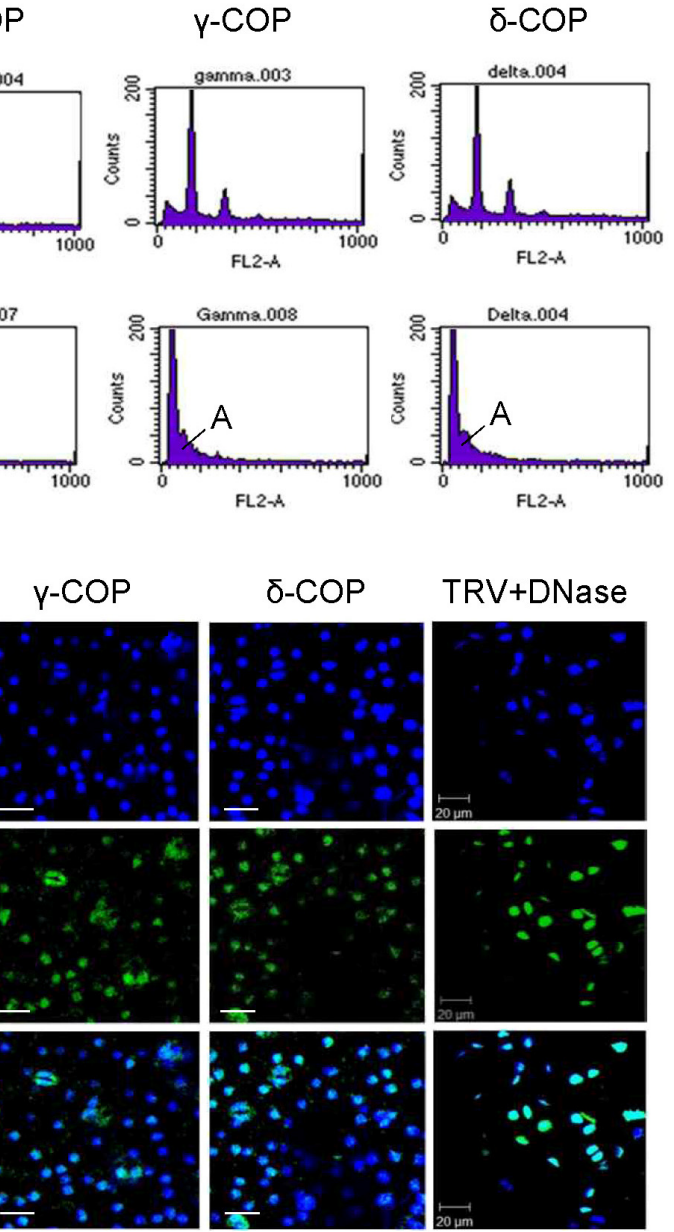
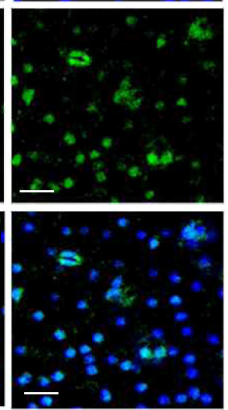

TRV+DNase

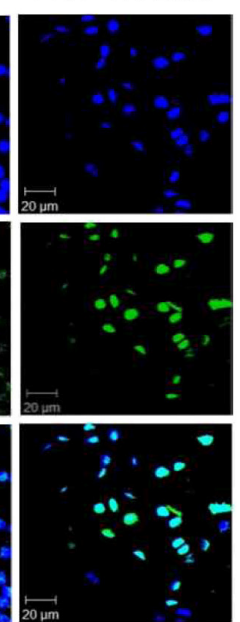

Fig. 3. Analyses of cell death phenotypes in COPI VIGS N. benthamiana plants. (A) Flow cytometry was performed with leaf nuclei isolated from TRV: $\beta$ '-COP, TRV: $\gamma$ COP, and TRV: $\delta$-COP VIGS plants and TRV control plants at 11 and 16 DAl. Approximately 10,000 nuclei were counted for each sample. A, apoptotic nuclei. (B) The TUNEL assay on TRV: $\beta$ '-COP, TRV: $\gamma-C O P$, and TRV: $\delta$-COP VIGS leaves was observed by confocal microscopy. Leaves were counterstained with DAPI to visualize nuclei. TRV and DNase-treated TRV leaves were used as negative and positive controls, respectively. Scale bars $=20$ $\mu \mathrm{m}$. and TRV: $\delta$-COP each contained a 504-bp N-terminal region, a 501-bp central region, and a 504-bp C-terminal region of their respective cDNAs (Fig. 2A). VIGS with all of these constructs resulted in growth retardation and acute cell death in leaves by forming necrotic lesions that spread from the leaf base to the tip (Fig. 2B). The necrotic spots appeared in leaves of the VIGS plants as early as 14 days after infiltration (DAI), and the plants usually perished within a month after infiltration. This abnormal phenotype has been observed reproducibly in almost all of the $>150 \mathrm{~N}$. benthamiana plants that have been subjected to COPI VIGS to date. VIGS with the control TRV, however, resulted in barely visible phenotypes. Semiquantitative reverse transcription PCR (RT-PCR) revealed significantly lower levels of endogenous transcripts of $\beta^{\prime}-, \gamma-$, and $\delta$-COP in the leaves of their respective VIGS plants, suggesting that gene silencing had occurred (Fig. 2C).

\section{Characterization of cell-death phenotypes in COPI-deficient plant cells}

We characterized the cell death phenotypes of the $\beta^{\prime}-, \gamma$-, and $\delta$-COP N. benthamiana VIGS plants (Fig. 3; Supplementary Figs. S4 and S5). DNA fragmentation caused by cell-deathspecific endonucleases is a hallmark feature of programmed cell death. We performed flow cytometry to determine the DNA content of nuclear suspensions from COPI VIGS plants, in comparison with TRV control (Fig. 3A). Most of the nuclei had a ploidy level of $2 \mathrm{C}$ in TRV leaves at 11 and $16 \mathrm{DAl}$. Although the leaf cells of the TRV: $\beta$ '-COP, TRV: $\gamma-C O P$, and TRV: $\delta-C O P$ plants exhibited normal DNA content at $11 \mathrm{DAl}$, apoptotic nuclei with fractional (sub-G1) DNA content were evident at 16 DAI, suggesting that DNA fragmentation had occurred (Fig. 3A).

We subsequently performed the TUNEL assay, which detects DNA breaks by inserting fluorescent nucleotides into the broken DNA (Gavrieli et al. 1992). Confocal laser scanning microscopy detected no fluorescence in the leaf nuclei of control TRV plants at $15 \mathrm{DAl}$. However, strong fluorescent signals were detected in TRV: $\beta$-COP, TRV: $\gamma-C O P$, and TRV: $\delta$-COP leaf nuclei as well as in DNase-treated TRV nuclei (positive control), suggesting that DNA fragmentation had occurred in those nuclei (Fig. 3B).

Modification of mitochondrial membrane permeability (MMP) is linked to activation of the programmed cell death pathway (Lam et al., 2001; Reape and McCabe, 2008). Thus, we monitored the MMP of leaf protoplasts from VIGS plants by using Tetramethylrhodamine methyl ester (TMRM) fluorescent probes that accumulate in mitochondria in proportion to the mitochondrial membrane potential. The average TMRM fluorescence of the TRV: $\beta^{\prime}-\mathrm{COP}, \mathrm{TRV}: \gamma-\mathrm{COP}$, and TRV: $\delta$-COP protoplasts was 4- to 10-fold lower than that of the TRV control at $15 \mathrm{DAl}$, suggesting reduced mitochondrial membrane potential (Supplementary Fig. S4). To test whether reactive oxygen species (ROS) are involved in the cell death of TRV: $\beta^{\prime}-\mathrm{COP}, \mathrm{TRV}: \gamma-\mathrm{COP}$ and TRV: $\delta$-COP plants, leaf protoplasts of the VIGS plants (15 

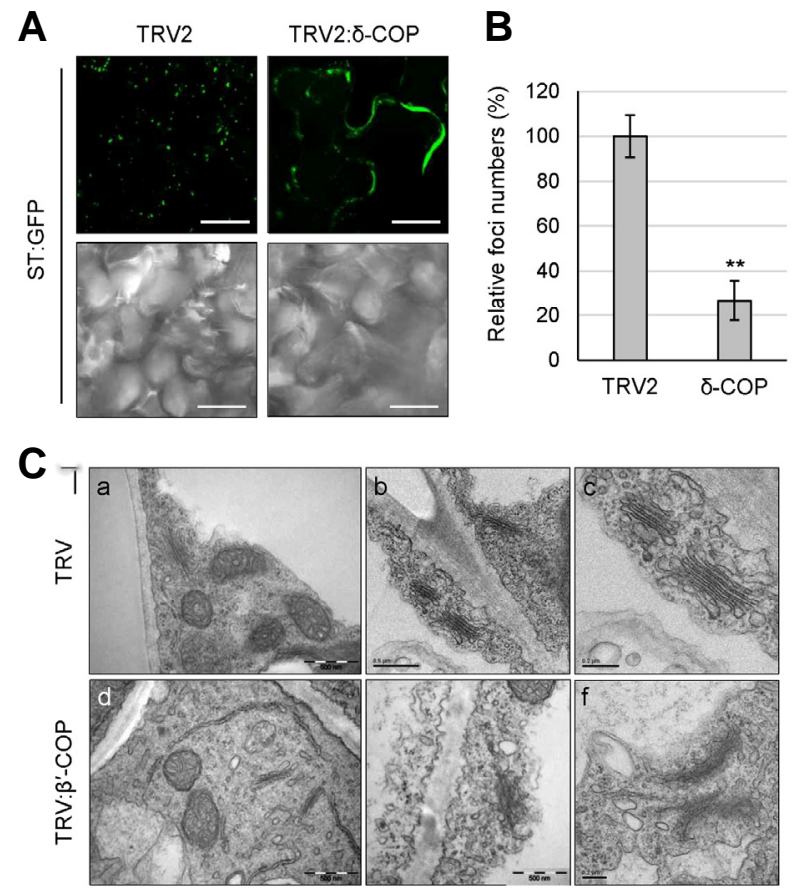

Fig. 4. Disruption of Golgi structure in COPI deficient plants. (A) VIGS was performed with Arabidopsis $\delta$-COP cDNA fragment in TRV2 vector using Arabidopsis transgenic plants expressing STGFP fusion protein as a Golgi marker. GFP fluorescence of leaf samples was observed by confocal microscopy at 12 DAl. Scale bars $=20 \mu \mathrm{m}$. (B) For quantification of the Golgi-specific foci shown in $(A), z$-sectioning images were taken serially at $0.5-\mu \mathrm{m}$ intervals (10 images). After 3-dimensional (3-D) reconstruction, the foci were counted using ImageJ. Approximately 300 foci were counted for each 3-D image, and 9 leaf samples were analyzed for each VIGS line for statistical analysis. Foci numbers of TRV2: $\delta$-COP VIGS plants were expressed relative to that of TRV2 control. Asterisks denote the statistical significance of the differences between TRV2: $\delta$-COP and TRV2 control samples: ${ }^{*} P \leq 0.05$; ${ }^{*} P \leq 0.01$. (C) Morphology of the Golgi complex in the leaves of the $N$. benthamiana TRV: $\beta^{\prime}$-COP VIGS plants (12 DAI) was observed by transmission electron microscopy (TEM). Scale bars $=0.5 \mu \mathrm{m}$ in $(a, b, d)$; $0.2 \mu \mathrm{m}$ in (c, e, f).

DAI) were incubated with $\mathrm{H}_{2} \mathrm{DCFDA}$, which produce green fluorescence in the presence of $\mathrm{H}_{2} \mathrm{O}_{2} . \mathrm{H}_{2}$ DCFDA fluorescence in the TRV: $\beta$ '-COP, TRV: $\gamma-C O P$, and TRV: $\delta$-COP protoplasts was 2.5- to 3-fold higher than in the TRV control, suggesting ROS involvement in the cell-death program of the COPIdepleted plant cells (Supplementary Fig. S5).

\section{COPI deficiency results in disassembly of the Golgi apparatus}

Since COPI subunits mainly localize to the Golgi (Fig. 1), we examined whether depletion of the COPI complex disrupts biogenesis of the Golgi before the affected leaf cells undergo programmed cell death (PCD). We used ST-GFP as the Golgi marker to observe Golgi patterns in live leaf cells. Transient expression of ST-GFP in VIGS plants through agro-infiltration can result in different expression levels of the marker protein in each VIGS plant. Thus, we instead performed VIGS in Ara-
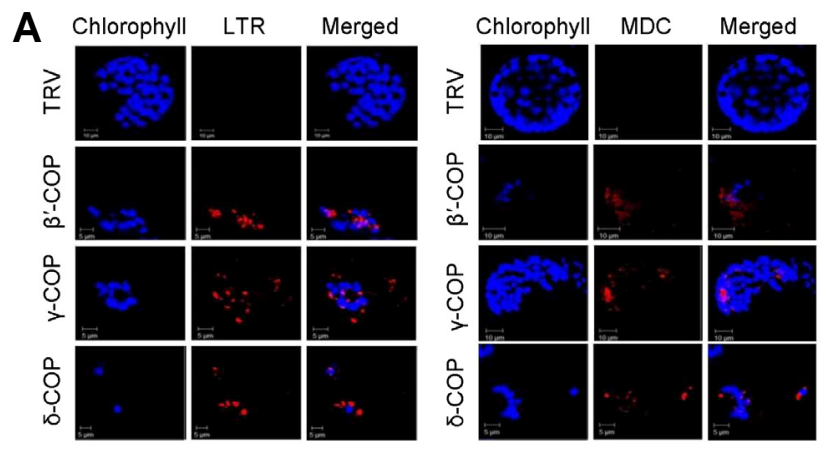

B
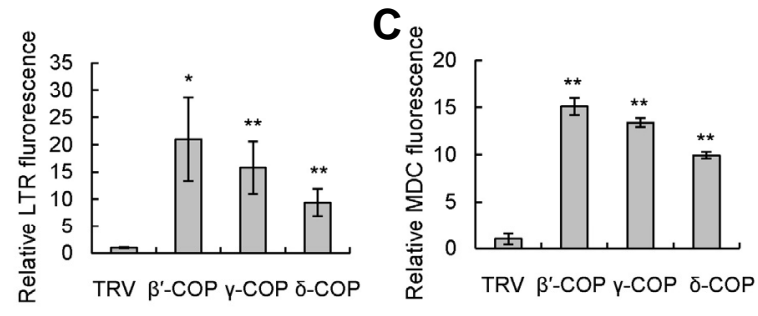

D

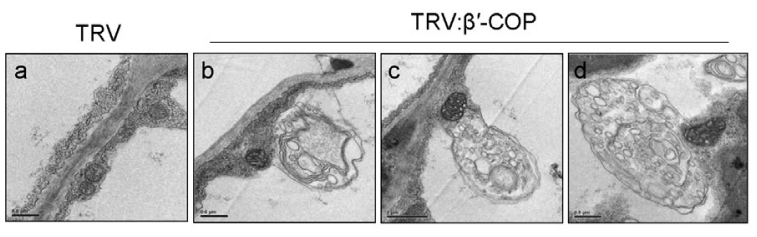

Fig. 5. Detection of autolysosomal structures in COPI VIGS $N$. benthamiana plants.(A) Lysotracker red (LTR) and monodansylcadaverine (MDC) staining of leaf protoplasts isolated from TRV: $\beta^{\prime}-$ COP, TRV: $\gamma-C O P$, and TRV: $\delta$-COP VIGS plants at 12 DAI. Representative confocal images are shown. Scale bars $=5 \mu \mathrm{m}$. (B) LTR fluorescence of leaf protoplasts from COPI VIGS plants shown in (A) was expressed relative to that of TRV control. Data represent means \pm SD of 30 individual protoplasts. Asterisks denote the statistical significance of the differences between COPI-silenced plants and TRV controls; ${ }^{*} P \leq 0.05$; ${ }^{*} P \leq 0.01$. (C) MDC fluorescence of leaf protoplasts from COPI VIGS plants shown in (A) was expressed relative to that of TRV control. Data represent means $\pm S D$ of 30 individual protoplasts. (D) Representative TEM images of the cytoplasm in mesophyll cells of TRV and TRV: $\beta^{\prime}$-COP VIGS plants at 12 DAl. Scale bars $=0.5 \mu \mathrm{m}$ in (a, b, d); $1 \mu \mathrm{m}$ in (c).

bidopsis transgenic plants that stably express ST-GFP (Min et al., 2013), using the Arabidopsis $\delta$-COP gene in the TRV2 VIGS vector. Plant phenotypes of $\delta$-COP VIGS in Arabidopsis were very similar to those in $N$. benthamiana. Confocal microscopy revealed that TRV2: $\delta$-COP leaf cells were deprived of Golgi-specific foci in the cytosol; instead, green fluorescence of ST-GFP was mainly observed in the periphery of the cells (Fig. $4 A)$. Indeed, the number of foci in the TRV2: $\delta$-COP leaf cells was reduced to about $27 \%$ of the number in the TRV2 control (Fig. 4B). These results suggest that COPI deficiency leads to disruption of the Golgi apparatus. Transmission electron microscopy (TEM) of transverse leaf sections from $N$. benthamiana VIGS plants revealed that TRV control cells contained wellorganized Golgi stacks consisting of multiple flattened cisternae. Abnormal or disrupted Golgi morphology was rarely observed in TRV cells. In contrast, leaf cells of TRV: $\beta$ '-COP plants (12 DAI) mostly contained disintegrating or less organized forms of Golgi 
A

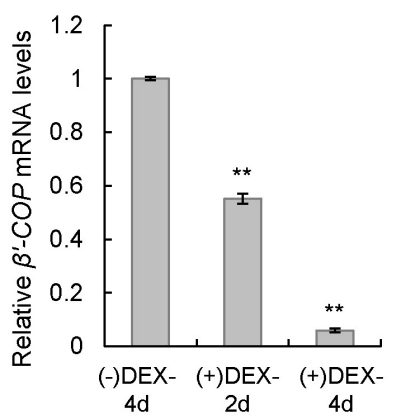

C

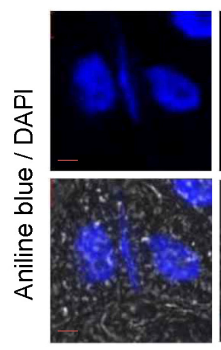

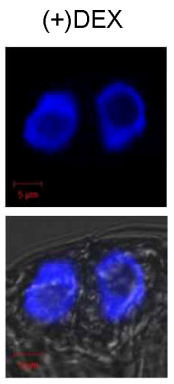

B
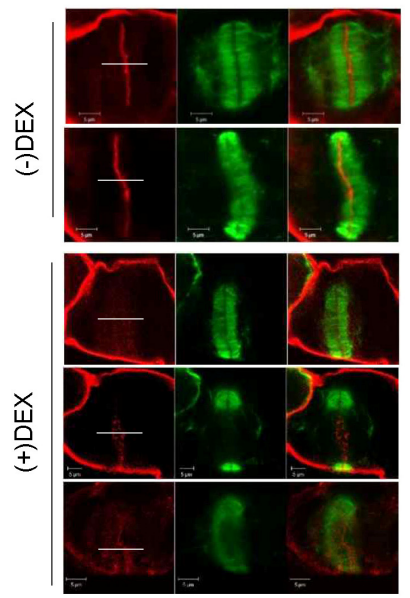

D

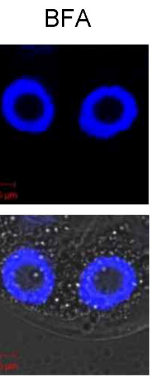

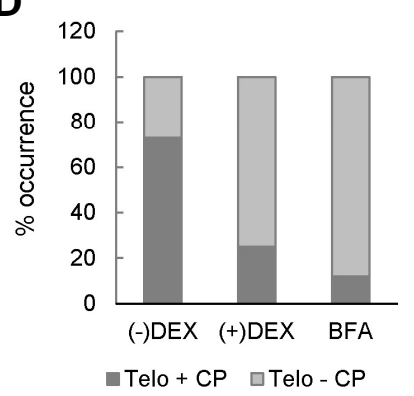

Fig. 6. Defective cell plate formation in DEX-inducible $\beta^{\prime}$-COP RNAi BY-2 cells. (A) Real-time quantitative RT-PCR was performed to determine the $\beta$-COP mRNA level in the RNAi BY-2 cells after 2 days $(2 \mathrm{~d})$ or 4 days $(4 \mathrm{~d})$ of $15 \mu \mathrm{M}$ DEX treatment. The transcript levels were expressed relative to that of $\mathrm{BY}-2$ cells ethanol-treated for 4 days [(-)DEX-4 d]. Data points represent means $\pm S D$ of three replicate experiments; ${ }^{*} P \leq 0.05$; ${ }^{*} P \leq 0.01$. (B) BY-2 cells were double-labeled with calcofluor staining (pseudo-colored red) and anti- $\alpha$-tubulin antibodies to visualize the cell plate and the phragmoplast, respectively, after 4 days of ethanol (-DEX) or DEX treatment. The right-most panels show the calcofluor fluorescence intensity profiles spanning the cell plate (white lines). Scale bars $=5 \mu \mathrm{m}$. (C) BY-2 cells were double-labeled with aniline blue and DAPI to visualize the cell plate and the nuclei, respectively. Representative telophase cells are shown. BY-2 cells were treated with $20 \mu \mathrm{M}$ BFA as positive control. Scale bars $=5 \mu \mathrm{m}$. (D) Telophase cells with (Telo $+\mathrm{CP}$ ) or without the newly forming cell plate (Telo - CP) shown in (C) were quantified $(\mathrm{n}=\sim 80$ for each sample). Values are expressed as percentage of total telophase cells counted. apparatus (79.3\%), although normal Golgi was also observed $(20.7 \%)$. Consistent with data from the mammalian system (Razi et al., 2009), these results demonstrate that COPI functions are required for maintaining the Golgi apparatus in plants.

\section{COPI deficiency causes accumulation of autolysosome- like structures}

Autophagy is a conserved catabolic pathway in eukaryotic cells that controls the recycling of bulk cytoplasmic materials (Bassham, 2007; Liu et al., 2005; Lum et al., 2005; Shin et al., 2014). During autophagy, cytoplasm is enclosed in autophagosomes and delivered to the lysosome or lytic vacuole for degradation. In tobacco, autophagosomes can fuse with small lysosomes or endosomes, where the contents can be degraded prior to fusion with the vacuole (Bassham, 2007). It has been reported that depletion of COPI subunits leads to the accumulation of autophagosomes in mammalian cells (Razi et al., 2009). To detect autophagy, leaf protoplasts of TRV, TRV: $\beta^{\prime}-$ COP, TRV: $\gamma-\mathrm{COP}$, and TRV: $\delta$-COP $N$. benthamiana VIGS plants at 12 DAl were stained with lysotracker red (LTR) or monodansylcadaverine (MDC), both of which stain acidic organelles such as autolysosomes and lytic vacuoles. LTR- and MDC-stained autolysosome-like particles were clearly visible in protoplasts from TRV: $\beta^{\prime}-\mathrm{COP}, \mathrm{TRV}: \gamma-\mathrm{COP}$, and TRV: $\delta-C O P$ VIGS plants, while staining was rarely observed in TRV control protoplasts (Fig. 5A). The LTR and MDC fluorescence in the protoplasts was quantified: $\beta^{\prime}, \gamma$, and $\delta$-COP-silenced protoplasts commonly exhibited levels of fluorescence that were over 10 times higher than that of TRV (Figs. 5B and 5C). Furthermore, transmission electron microscopy (TEM) revealed that TRV: $\beta^{\prime}$-COP leaf cells at 12 DAl exhibited abundant autophagosome-like double-membrane vesicles containing elec- tron-dense materials, while such structures were only sporadically observed in control TRV cells (Fig. 5D).

\section{Defective cell plate formation in DEX-inducible $\beta^{\prime}$-COP RNAi BY-2 cells}

Cell plate formation is a plant-specific process that requires deposition of vesicles derived from the Golgi in the middle of the division zone (Jürgens, 2005a). The $\gamma$-COP protein was shown to localize near the cell plate in maize roots based on immunofluorescence (Couchy et al., 2003). In order to examine the effects of COPI depletion in cell plate formation, DEXinducible $\beta$-COP RNAi transgenic BY-2 cell lines were generated. The $\beta^{\prime}-\mathrm{COP}$ mRNA level of the RNAi BY-2 cells was reduced to about $57 \%$ of the level of ethanol-treated cells (-DEX) after 2 days of $15 \mu \mathrm{M}$ DEX treatment, and the level was further reduced to less than $10 \%$ of the (-)DEX level after 4 days of DEX treatment (Fig. 6A). To observe cell plate formation, the $\beta^{\prime}$ COP RNAi BY-2 cells were fixed and immunolabeled with anti$\alpha$-tubulin antibodies, and then stained with calcofluor-white, which stains cellular structures containing cellulose, for confocal laser scanning microscopy. The calcofluor fluorescence intensity profile spanning the cell plate (marked with white lines) is also shown. (-)DEX BY-2 cells at telophase exhibited newly forming cell plates (calcofluor staining) and normal assembly of phragmoplasts ( $\alpha$-tubulin labeling) (Fig. 6B). However, cell plates were missing or defective in DEX-treated cells despite normal patterns of phragmoplasts (Fig. 6B; Supplementary Fig. S6).

The absence of cell plate formation during cytokinesis leads to binucleate cells, and these types of binucleate cells are observed in brefeldin A (BFA)-treated cells (Ritzenthaler et al., 2002; Yasuhara, 2005). Notably, blockage of cell plate formation by BFA treatment coincides with the disruption of the 
Golgi apparatus (Ritzenthaler et al., 2002). The cell plate defect of $\beta^{\prime}$-COP-silenced BY-2 cells was further examined using aniline blue staining, which detects callose deposited on the forming cell plate (Gunning and Wick, 1985), along with DAPI staining to visualize nuclei (Fig. 6C). The cell plate defect was then quantified using confocal microscopy (Fig. 6D). BFAtreated BY-2 cells were used as positive control. DEX-treated BY-2 cells exhibited a significantly higher percentage of telophase cells without cell plates $(\sim 71 \%)$, similar to BFA-treated cells $(\sim 88 \%)$, as compared to (-)DEX cells ( $27 \%)$ (Figs. $6 \mathrm{C}$ and $6 \mathrm{D})$. These results collectively suggest that intact COPI functions are crucial for the cell plate formation.

\section{DISCUSSION}

In this study, we employed VIGS and RNAi to observe the physiological effects of COPI deficiency in plants. We showed that the COPI coatomer complex plays an essential role in plant growth and survival as the depletion of its subunits leads to growth arrest and early onset of plant death. The $\beta^{\prime}-, \gamma$, and $\delta$ COP subunits localize to the Golgi apparatus and interact with each other there. Silencing of $\beta^{\prime}, \gamma$, and $\delta$-COP genes using VIGS results in disassembly of the Golgi apparatus and accumulation of autolysosome-like structures. Finally, RNAi inhibition of $\beta-C O P$ in tobacco $\mathrm{BY}-2$ cells causes defective cell plate formation. These results suggest that COPI functions are critical for Golgi maintenance and cell plate formation in higher plants.

COPI vesicles are essential structures in eukaryotic cells that mediate the retrograde transport of various cargo proteins in the endomembrane system. The heptameric COPI complex is recruited to the Golgi membranes by ARF1 GTPase, and the resulting COPI vesicles transport proteins to the ER or to the cis-Golgi under regulation of ARF1 (Beck et al., 2009; HaraKuge et al., 1994; Jackson, 2014). However, the possibility of COPI vesicle involvement in anterograde transport between Golgi cisternae remains controversial (Faso et al., 2009). Recent structural studies have shown that binding of the COPI complex to the ARF1 GTPase is mediated by the $\delta$ - and $\gamma$-COP subunits (Yu et al., 2012), while $\beta^{\prime}-\mathrm{COP}$ is known to bind the dilysine motif of ER-retention proteins (Jackson et al., 2012).

In this study, the depletion of COPI subunits in plants caused disruption of the Golgi complex and accumulation of autolysosome-like structures (Figs. 4 and 5). Consistent with the results, loss of $\beta^{\prime}-, \alpha-$, or $\beta$-COP by siRNA in mammalian cells led to fragmentation of the Golgi and the accumulation of autophagosomes (Razi et al., 2009). Similarly, degradation of temperature-sensitive $\varepsilon$-COP at the non-permissive temperature in a $\mathrm{CHO}$ cell line resulted in the loss of the Golgi complex (Guo et al., 1994). BFA is a chemical known to disrupt the Golgi apparatus. Studies in animals have shown that BFA inhibits the guanine nucleotide exchange factor (GEF) of the ARF GTPases, which in turn inhibits formation of COPI vesicles (Donaldson et al., 1992). BFA treatment in tobacco BY-2 cells led to disruption of the Golgi beginning from the cis-cisternae, and subsequently resulted in an ER-Golgi hybrid (Ritzenthaler et al., 2002). Interestingly, the Golgi-associated $\gamma$-COP subunit completely disappeared and became dispersed throughout the cytoplasm in BY2 cells upon BFA treatment (Ritzenthaler et al., 2002). The mechanism in which COPI deficiency causes autophagosome accumulation has been studied in mammalian cells (Razi et al. 2009). Although COPI vesicles are best known for their role in vesicle transport between the Golgi and ER, COPI subunits are also involved in maintaining endosomal/lysosomal functions (Gu et al., 1997; Whitney et al., 1995). Autophagy requires the fusion of autophagosomes with late endosomes for content degradation, and the loss of COPI subunits $\left(\beta^{\prime}, \alpha\right.$, or $\left.\beta\right)$ was observed to cause inhibition of early endosome function, resulting in the accumulation of autophagosomes in mammalian cells (Razi et al., 2009).

A deficiency of COPI subunits induced programmed cell death (PCD) in N. benthamiana leaf cells, accompanied by DNA fragmentation, reduced mitochondrial membrane potential, and an increase in cellular ROS level (Fig. 3; Supplementary Figs. S4 and S5). In zebrafish, a defect in $\alpha-, \beta$-, or $\beta^{\prime}$-COP led to embryo lethality; in the mutant embryo, export from the endoplasmic reticulum (ER) was blocked, the Golgi structure was disrupted, and widespread apoptosis was induced (Coutinho et al., 2004). Interestingly, these results suggest that a defective COPI system can affect anterograde transport from the ER to the Golgi. Indeed, retrograde trafficking plays a critical role in recycling ER-resident machinery; a failure to retrieve these proteins by a defective retrograde pathway can result in a concomitant block in anterograde transport (Lee et al., 2004; 2013; Reilly et al., 2001). Perturbations in ER functions disrupt protein folding, leading to the accumulation of protein aggregates and misfolded proteins, a condition referred to as ER stress. Excessive ER stress can induce apoptosis in animals and programmed cell death in plants, which involves DNA fragmentation, cytochrome $c$ release, and induction of caspase activity (Szegezdi et al., 2006; Urade, 2009; Watanabe and Lam, 2008). Induction of PCD in COPI-deficient leaf cells may reflect severe ER stress within the cells, possibly caused by the trafficking defects. Supporting our proposal, Zerangue et al. (2001) suggested that retrograde traffic via the COPI system contributes to ER quality control.

COPI-depleted leaf cells accumulated autolysosome-like structures before the onset of acute cell death (Fig. 5). The exact role of autophagy as a pro-survival or pro-death process has been under debate. Autophagy-defective Arabidopsis mutants, i.e. atg mutants, exhibited early senescence and precocious cell death, and are more sensitive to stresses, supporting a pro-survival function of autophagy (Avila-Ospina et al., 2014; Hanaoka et al., 2002; Phillips et al., 2008; Xiong et al., 2005). However, the atg5 autophagy-deficient mutation blocked PCD during tracheary element development, and the process was promoted by increased autophagic activity (Kwon et al., 2010). The results are reminiscent of the findings in Drosophila that autophagy is essential for developmental processes such as salivary gland cell degradation and midgut cell death (Berry et al., 2007; Denton et al., 2009). Thus, autophagy can effectuate cell death pathways involved in development of eukaryotic organisms, supporting a pro-death mechanism. Furthermore, contradictory evidence regarding functions of autophagy in plant immunity has been reported. Liu et al. (2005) reported that autophagy contributes to resistance and restricts the spread of PCD associated with the pathogen-triggered hypersensitive response (HR), thus functioning as a pro-survival pathway. Paradoxically, it has been reported that autophagic components contribute to receptor-mediated HR PCD (Hofius et al., 2009; 2011). These results collectively suggest that intricate balance between pro-survival and pro-death mechanisms operates within autophagy pathways. Accumulation of autolysosome-like structures in COPI-depleted leaf cells may be considered as a last effort to deal with prolonged ER stress and to prevent acute cell death. Further experiments would reveal the role of COPI in autophagy and its influence on PCD observed in COPI-deficient plants.

In plant cells, phragmoplasts control cytokinesis by function- 
ing as a framework to transport cell-plate-destined vesicles to the division plane (Van Damme et al., 2008). However, the origins of the cell-plate-building vesicles have not been clearly demonstrated. It has been suggested that both secretory and endocytic pathways contribute to cell plate formation (Dhonukshe et al., 2006; Reichardt et al., 2007; Song et al., 2006; 2012; Van Damme et al., 2008). During mitosis, Golgi stacks accumulate in a subcortical ring, referred to as the Golgi belt, which stimulates the directed delivery of Golgi-derived vesicles to the cell plate. Treatment of a dividing cell with the $V$ ATPase inhibitor concanamycin A, which blocks all membrane trafficking at the TGN but does not interfere with the formation of endocytic vesicles at the plasma membrane, resulted in disruption of cytokinesis and formation of binucleate cells (Reichardt et al., 2007). This result clearly demonstrates that secretory trafficking pathway plays an essential role in cell plate formation. The cell plate, however, is enriched in clathrin-coated vesicles (CCV) and diverse proteins involved in CCV-mediated endocytosis, suggesting that active endocytosis takes place near the cell plate (Ito et al., 2012; Jürgens, 2005b; Song et al., 2006; 2012). Indeed, endocytic markers, such as FM4-64, label the cell plate at the initiation stage of biogensis, and inhibition of endocytosis consequently interferes with cell plate formation (Dhonukshe et al., 2006). More recently, it has been reported that endocytosis restricts the cytokinesis-specific syntaxin KNOLLE to the cell division plane during late cytokinesis (Boutté et al., 2009). Collectively, these results suggest critical involvement of both secretory and endocytic trafficking in plant cell plate formation.

Previously, COPI subunit epitopes were found to localize near the cell plate in maize roots (Couchy et al., 2003). In this study, we present evidence that COPI vesicles play an important role in cell plate formation in BY-2 cells (Fig. 6). Our results suggest that COPI vesicles may function not only in the retrograde transport between the Golgi and the ER but also at the cell plate, possibly modulating the recycling movement between the newly forming cell plate and the Golgi stacks or ER. Alternatively, COPI depletion may indirectly affect the cell plate formation; COP1-mediated maintenance of functional Golgi may be crucial for the cell plate formation. Since COPI and ARF1 are present in early endosomes and involved in endosome maturation (Gu et al., 1997; Huotari and Helenius, 2011; Whitney et al., 1995), there is a possibility that COPI may indirectly affect cell plate formation by modulating endocytic pathway. Interestingly, the role of COPI in cytokinesis appears to be conserved in other eukaryotes. It has been reported that COPI-mediated membrane trafficking is required for cytokinesis in Drosophila male meiotic divisions (Kitazawa et al., 2012). The final step of cytokinesis in Drosophila and other animal cells involves filling the gap in the midbody, which was formed between the cleavage furrows (Darenfed and Mandato, 2005). COPI vesicles may be commonly involved in plant and animal cells as the molecular machinery to form a membranous barrier that separates the daughter cells. Deciphering the molecular networks of the COPI complex and its interactions is likely to be essential for understanding the functions of COPI vesicles in cell plate formation.

Note: Supplementary information is available on the Molecules and Cells website (www.molcells.org).

\section{ACKNOWLEDGMENTS}

The authors declare no conflict of interest. The research was supported by the Next-Generation BioGreen21 Program for Agriculture \& Technology Development Project [No. PJ011147 (PMBC)] from the Rural Development Administration, by the Mid-Career Researcher Program (No. 2014051690) and by the Basic Science Research Program (No. 2014023933) from the National Research Foundation of Republic of Korea. H.-K. Ahn was supported by the Global Ph.D Fellowship Program (project No. 2011-0031010) from the National Research Foundation of Republic of Korea.

\section{REFERENCES}

Ahn, C.S., Han, J.A., Lee, H.S., Lee, S., and Pai, H.-S. (2011). The PP2A regulatory subunit Tap46, a component of the TOR signaling pathway, modulates growth and metabolism in plants. Plant Cell 23, 185-209.

Avila-Ospina, L., Moison, M., Yoshimoto, K., and MasclauxDaubresse, C. (2014). Autophagy, plant senescence, and nutrient recycling. J. Exp. Bot. 65, 3799-3811.

Assaad, F.F. (2001). Plant cytokinesis. Exploring the links. Plant Physiol. 126, 509-516.

Bassham, D.C. (2007). Plant autophagy-more than a starvation response. Curr. Opin. Plant Biol. 10, 587-593.

Bassham, D.C., Brandizzi, F., Otegui, M.S., and Sanderfoot, A.A. (2008). The secretory system of Arabidopsis. The Arabidopsis Book 6, e0116

Beck, R., Rawet, M., Wieland, F.T., and Cassel, D. (2009). The COPI system: molecular mechanisms and function. FEBS Lett. 583, 2701-2709.

Berry, D.L., and Baehrecke, E.H. (2007). Growth arrest and autophagy are required for salivary gland cell degradation in Drosophila. Cell 131, 1137-1148.

Boutté, Y., Frescatada-Rosa, M., Men, S., Chow, C.M., Ebine, K., Gustavsson, A., Johansson, L., Ueda, T., Moore, I., Jürgens, G., et al. (2009). Endocytosis restricts Arabidopsis KNOLLE syntaxin to the cell division plane during late cytokinesis. EMBO J. 29, 546-558.

Burch-Smith, T.M., Schiff, M., Liu, Y., and Dinesh-Kumar, S.P. (2006). Efficient virus-induced gene silencing in Arabidopsis. Plant Physiol. 142, 21-27.

Couchy, I., Bolte, S., Crosnier, M.T., Brown, S., and SatiatJeunemaitre, B. (2003). Identification and localization of a beta-COP-like protein involved in the morphodynamics of the plant Golgi apparatus. J. Exp. Bot. 54, 2053-2063.

Coutinho, P., Parsons, M.J., Thomas, K.A., Hirst, E.M., Saude, L., Campos, I., Williams, P.H., and Stemple, D.L. (2004). Differential requirements for COPI transport during vertebrate early development. Dev. Cell 7, 547-558.

Darenfed, H., and Mandato, C.A. (2005). Wound-induced contractile ring: a model for cytokinesis. Biochem. Cell Biol. 83, 711-720.

Day, K.J., Staehelin, L.A., and Glick, B.S. (2013). A three-stage model of Golgi structure and function. Histochem. Cell. Biol. $140,239-249$.

Denton, D., Shravage, B., Simin, R., Mills, K., Berry, D.L., Baehrecke, E.H., and Kumar, S. (2009). Autophagy, not apoptosis, is essential for midgut cell death in Drosophila. Curr. Biol. 19, 1741-1746.

Dhonukshe, P., Baluska, F., Schlicht, M., Hlavacka, A., Samaj, J. Friml, J., and Gadella, T.W. Jr. (2006). Endocytosis of cell surface material mediates cell plate formation during plant cytokinesis. Dev. Cell 10, 137-150.

Donaldson, J.G., Finazzi, D., and Klausner, R.D. (1992). Brefeldin A inhibits Golgi membrane-catalysed exchange of guanine nucleotide onto ARF protein. Nature 360, 350-352.

Donohoe, B.S., Kang, B.H., and Staehelin, L.A. (2007). Identification and characterization of COPla- and COPlb-type vesicle classes associated with plant and algal Golgi. Proc. Natl. Acad. Sci. USA 104, 163-168.

Faso, C., Boulaflous, A., and Brandizzi, F. (2009). The plant Golgi apparatus:last 10 years of answered and open questions. FEBS Lett. 583, 3752-3757. 
Frigerio, L., Hinz, G., and Robinson, D.G. (2008). Multiple vacuoles in plant cells:rule or exception? Traffic 9, 1564-1570.

Gao, C., Yu, C.K., Qu, S., San, M.W., Li, K.Y., Lo, S.W., and Jiang, L. (2012). The Golgi-localized Arabidopsis endomembrane protein12 contains both endoplasmic reticulum export and Golgi retention signals at its C terminus. Plant Cell 24, 20862104.

Gao, C., Cai, Y., Wang, Y., Kang, B.H., Aniento, F., Robinson, D.G., and Jiang, L. (2014). Retention mechanisms for ER and Golgi membrane proteins. Trends Plant Sci. 19, 508-515.

Gavrieli, Y., Sherman, Y., and Ben-Sasson, S.A. (1992). Identification of programmed cell death in situ via specific labeling of nuclear DNA fragmentation. J. Cell Biol. 119, 493501.

Geldner, N., Anders, N., Wolters, H., Keicher, J., Kornberger, W. Muller, P., Delbarre, A., Ueda, T., Nakano, A., and Jürgens, G. (2003). The Arabidopsis GNOM ARF-GEF mediates endosomal recycling, auxin transport, and auxin-dependent plant growth. Cell 112, 219-230.

Gu, F., Aniento, F., Parton, R.G., and Gruenberg, J. (1997). Functional dissection of COP-I subunits in the biogenesis of multivesicular endosomes. J. Cell Biol. 139, 1183-1195.

Gunning, B.E., and Wick, S.M. (1985). Preprophase bands, phragmoplasts, and spatial control of cytokinesis. J. Cell Sci. 2, 157-179.

Guo, Q., Vasile, E., and Krieger, M. (1994). Disruptions in Golgi structure and membrane traffic in a conditional lethal mammalian cell mutant are corrected by epsilon-COP. J. Cell Biol. 125, 1213-1224.

Hanaoka, H., Noda T., Shirano, Y., Kato T., Hayashi H., Shibata D., Tabata S., and Ohsumi, Y. (2002). Leaf senescence and starvation-induced chlorosis are accelerated by the disruption of an Arabidopsis autophagy gene. Plant Physiol. 129, 11811193

Hara-Kuge, S., Kuge, O., Orci, L., Amherdt, M., Ravazzola, M., Wieland, F.T., and Rothman, J.E. (1994). En bloc incorporation of coatomer subunits during the assembly of COP-coated vesicles. J. Cell Biol. 124, 883-892.

Hofius, D., Schultz-Larsen, T., Joensen, J., Tsitsigiannis, D.I., Petersen, N.H., Mattsson, O., Jørgensen, L.B., Jones, J.D., Mundy, J., and Petersen, M. (2009). Autophagic components contribute to hypersensitive cell death in Arabidopsis. Cell 137, 773-783.

Hofius, D., Munch, D., Bressendorff, S., Mundy, J., and Petersen, M. (2011). Role of autophagy in disease resistance and hypersensitive response-associated cell death. Cell Death Differ. 18, 1257-1262.

Huotari, J., and Helenius, A. (2011). Endosome maturation. EMBO J. 30, 3481-3500.

Ito, E., Fujimoto, M., Ebine, K., Uemura, T., Ueda, T., and Nakano, A. (2012). Dynamic behavior of clathrin in Arabidopsis thaliana unveiled by live imaging. Plant J. 69, 204-216.

Jackson, L.P. (2014). Structure and mechanism of COPI vesicle biogenesis. Curr. Opin. Cell Biol. 29, 67-73.

Jackson, L.P., Lewis, M., Kent, H.M., Edeling, M.A., Evans, P.R., Duden, R., and Owen, D.J. (2012). Molecular basis for recognition of dilysine trafficking motifs by COPI. Dev. Cell 23 , 1255-1262.

Jürgens, G. (2004). Membrane trafficking in plants. Annu. Rev. Cell Dev. Biol. 20, 481-504.

Jürgens, G. (2005a). Cytokinesis in higher plants. Annu. Rev. Plant. Biol. 56, 281-299.

Jürgens, G. (2005b). Plant cytokinesis:fission by fusion. Trends Cell Biol. 15, 277-283.

Kang, Y.W., Lee, J.Y., Jeon, Y., Cheong, G.W., Kim, M., and Pai, H.-S. (2010). In vivo effects of NbSiR silencing on chloroplast development in Nicotiana benthamiana. Plant Mol. Biol. 72, 569-583.

Kang, Y.W., Jeon, Y., and Pai, H.-S. (2012). Characterization of cell death induced by NbBPS1 silencing in Nicotiana benthamiana. Mol. Cells 34, 185-191.

Kim, M., Lim, J.H., Ahn, C.S., Park, K., Kim, G.T., Kim, W.T., and Pai, H.-S. (2006). Mitochondria-associated hexokinases play a role in the control of programmed cell death in Nicotiana benthamiana. Plant Cell 18, 2341-2355.
Kitazawa, D., Yamaguchi, M., Mori, H., and Inoue, Y.H. (2012). COPI-mediated membrane trafficking is required for cytokinesis in Drosophila male meiotic divisions. J. Cell Sci. $125,3649-3660$

Kwon, S.I., Cho, H.J., Jung, J.H., Yoshimoto, K., Shirasu, K., and Park, O.K. (2010). The Rab GTPase RabG3b functions in autophagy and contributes to tracheary element differentiation in Arabidopsis. Plant J. 64, 151-164.

Lam, E., Kato, N., and Lawton, M. (2001). Programmed cell death, mitochondria and the plant hypersensitive response. Nature 411, 848-853.

Lee, M.C.S., Miller, E.A., Goldberg, J., Orci, L., and Schekman, R. (2004). Bi-directional protein transport between the ER and Golgi. Annu. Rev. Cell Dev. Biol. 20, 87-123.

Lee, J.Y., Sarowar, S., Kim, H.S., Kim, H., Hwang, I., Kim, Y.J., and Pai, H.-S. (2013). Silencing of Nicotiana benthamiana Neuroblastoma-Amplified Gene causes ER stress and cell death. BMC Plant Biol. 13, 69.

Liu, Y., Schiff, M., Czymmek, K., Talloczy, Z., Levine, B., and Dinesh-Kumar, S.P. (2005). Autophagy regulates programmed cell death during the plant innate immune response. Cell 121, 567-577.

Lum, J.J., DeBerardinis, R.J., and Thompson, C.B. (2005). Autophagy in metazoans:cell survival in the land of plenty. Nat. Rev. Mol. Cell Biol. 6, 439-448.

McFarlane, H.E., Watanabe, Y., Yang, W., Huang, Y., Ohlrogge, J., and Samuels, A.L. (2014). Golgi- and trans-Golgi networkmediated vesicle trafficking is required for wax secretion from epidermal cells. Plant Physiol. 164, 1250-1260.

McMichael, C.M., and Bednarek, S.Y. (2013). Cytoskeletal and membrane dynamics during higher plant cytokinesis. New Phytol. 197, 1039-1057

Min, M.K., Jang, M., Lee, M., Lee, J., Song, K., Lee, Y., Choi, K.Y., Robinson, D.G., and Hwang, I. (2013). Recruitment of Arf1GDP to Golgi by Glo3p-type ArfGAPs is crucial for golgi maintenance and plant growth. Plant Physiol. 161, 676-691.

Montesinos, J.C., Pastor-Cantizano, N., Robinson, D.G., Marcote, M.J., and Aniento, F. (2014). Arabidopsis p24delta5 and p24delta9 facilitate Coat Protein I-dependent transport of the K/HDEL receptor ERD2 from the Golgi to the endoplasmic reticulum. Plant J. 80, 1014-1030.

Nebenführ, A., Frohlick, J.A., and Staehelin, L.A. (2000). Redistribution of Golgi stacks and other organelles during mitosis and cytokinesis in plant cells. Plant Physiol. 124, 135151

Nelson, B.K., Cai X., and Nebenführ A. (2007). A multi-color set of in vivo organelle markers for colocalization studies in Arabidopsis and other plants. Plant J. 51, 1126-1136.

Nishihama, R., Soyano, T., Ishikawa, M., Araki, S., Tanaka, H. Asada, T., Irie, K., Ito, M., Terada, M., Banno, H., et al. (2002). Expansion of the cell plate in plant cytokinesis requires a kinesin-like protein/MAPKKK complex. Cell 109, 87-99.

Papanikou, E., and Glick, B.S. (2014). Golgi compartmentation and identity. Curr. Opin. Cell Biol. 29, 74-81.

Paul, M.J., and Frigerio, L. (2007). Coated vesicles in plant cells. Semin. Cell Dev. Biol. 18, 471-478.

Pimpl, P., Movafeghi, A., Coughlan, S., Denecke, J., Hillmer, S., and Robinson, D.G. (2000). In situ localization and in vitro induction of plant COPI-coated vesicles. Plant Cell 12, 22192236.

Ratcliff, F., Martin-Hernandez, A.M., and Baulcombe, D.C. (2001). Tobacco rattle virus as a vector for analysis of gene function by silencing. Plant J. 25, 237-245.

Razi, M., Chan, E.Y., and Tooze, S.A. (2009). Early endosomes and endosomal coatomer are required for autophagy. J. Cell Biol. 185, 305-321.

Reape, T.J., and McCabe, P.F. (2008). Apoptotic-like programmed cell death in plants. New Phytol. 180, 13-26.

Reichardt, I., Stierhof, Y.-D., Mayer, U., Richter, S. Schwarz, H., Schumacher, K., and Jürgens, G. (2007). Plant cytokinesis requires de novo secretory trafficking but not endocytosis. Curr. Biol. 17, 2047-2053.

Reilly, B.A., Kraynack, B.A., VanRheenen, S.M., and Waters, M.G. (2001). Golgi-to-endoplasmic reticulum (ER) retrograde traffic in yeast requires Dsl1p, a component of the ER target site that 
interacts with a COPI coat subunit. Mol. Biol. Cell 12, 37833796.

Ritzenthaler, C., Nebenführ, A., Movafeghi, A., Stussi-Garaud, C., Behnia, L., Pimpl, P., Staehelin, L.A., and Robinson, D.G. (2002). Reevaluation of the effects of brefeldin A on plant cells using tobacco Bright Yellow 2 cells expressing Golgi-targeted green fluorescent protein and COPI antisera. Plant Cell 14, 237-261.

Ruiz, M.T., Voinnet, O., and Baulcombe, D.C. (1998). Initiation and maintenance of virus-induced gene silencing. Plant Cell 10, 937-946.

Shin, K.D., Lee, H.N., and Chung, T. (2014). A revised assay for monitoring autophagic flux in Arabidopsis thaliana reveals involvement of AUTOPHAGY-RELATED9 in autophagy. Mol. Cells 37, 399-405.

Song, J., Lee, M.H., Lee, G.J., Yoo, C.M., and Hwang, I. (2006). Arabidopsis EPSIN1 plays an important role in vacuolar trafficking of soluble cargo proteins in plant cells via interactions with clathrin, AP-1, VTI11, and VSR1. Plant Cell $18,2258-2274$

Song, K., Jang, M., Kim, S.Y., Lee, G., Lee, G.J., Kim, D.H., Lee, Y., Cho, W., and Hwang, I. (2012). An A/ENTH domaincontaining protein functions as an adaptor for clathrin-coated vesicles on the growing cell plate in Arabidopsis root cells. Plant Physiol. 159, 1013-1025.

Staehelin, L.A., and Hepler, P.K. (1996). Cytokinesis in higher plants. Cell 84, 821-824.

Szegezdi, E., Logue, S.E., Gorman, A.M., and Samali, A. (2006). Mediators of endoplasmic reticulum stress-induced apoptosis. EMBO Rep. 7, 880-885.

Urade, R. (2009). The endoplasmic reticulum stress signaling pathways in plants. Biofactors 35, 326-331.

Van Damme, D., Coutuer, S., De Rycke, R., Bouget, F.Y., Inzé, D., and Geelen, D. (2006). Somatic cytokinesis and pollen maturation in Arabidopsis depend on TPLATE, which has domains similar to coat proteins. Plant Cell 18, 3502-3518.
Van Damme, D., Inzé, D., and Russinova, E. (2008). Vesicle trafficking during somatic cytokinesis. Plant Physiol. 147, 1544-1552.

Walter, M., Chaban, C., Schutze, K., Batistic, O., Weckermann, K. Nake, C., Blazevic, D., Grefen, C., Schumacher, K., Oecking, C., et al. (2004). Visualization of protein interactions in living plant cells using bimolecular fluorescence complementation. Plant J. 40, 428-438.

Watanabe, N., and Lam, E. (2008). BAX inhibitor-1 modulates endoplasmic reticulum stress-mediated programmed cell death in Arabidopsis. J. Biol. Chem. 283, 3200-3210.

Whitney, J.A., Gomez, M., Sheff, D., Kreis, T.E., and Mellman, I. (1995). Cytoplasmic coat proteins involved in endosome function. Cell 83, 703-713.

Xiong, Y., Contento, A.L., and Bassham, D.C. (2005). AtATG18a is required for the formation of autophagosomes during nutrient stress and senescence in Arabidopsis thaliana. Plant J. 42, 535-546.

Yasuhara, H. (2005). Caffeine inhibits callose deposition in the cell plate and the depolymerization of microtubules in the central region of the phragmoplast. Plant Cell Physiol. 46, 1083-1092.

Yoshimoto, K., Jikumaru, Y., Kamiya, Y., Kusano, M., Consonni, C., Panstruga, R., Ohsumi, Y., and Shirasua, K. (2009). Autophagy negatively regulates cell death by controlling NPR1-dependent salicylic acid signaling during senescence and the innate immune response in Arabidopsis. Plant Cell 21, 2914-2927.

Yu, X., Breitman, M., and Goldberg, J. (2012). A structure-based mechanism for Arf1-dependent recruitment of coatomer to membranes. Cell 148, 530-542.

Zerangue, N., Malan, M.J., Fried, S.R., Dazin, P.F., Jan, Y.N., Jan, L.Y., and Schwappach, B. (2001). Analysis of endoplasmic reticulum trafficking signals by combinatorial screening in mammalian cells. Proc. Natl. Acad. Sci. USA 98, 2431-2436. 